\title{
Lugares turísticos en movimiento: desplazamiento y recorridos guiados en Salta (Argentina)
}

\author{
Claudia Alejandra Troncoso ${ }^{1}$ \\ Consejo Nacional de Investigaciones Científicas y Técnicas \\ Universidad de Buenos Aires \\ @ [ claudia.a.troncoso@gmail.com ]
}

RECIBIDO 30-06-2021

ACEPTADO 12-08-2021

Cita sugerida: Troncoso, C. A. (2021). Lugares turísticos en movimiento: desplazamiento y recorridos guiados en Salta (Argentina). Revista Huellas, Volumen 25, № 2, Instituto de Geografía, EdUNLPam: Santa Rosa. Recuperado a partir de: http://cerac.unlpam.edu.ar/index.php/huellas

DOI: http://dx.doi.org/10.19137/huellas-2021-2527

\section{Resumen}

El artículo aborda el papel que juega el movimiento vinculado al turismo en la conformación como destino de la ciudad de Salta (Argentina). Para ello se observan las prácticas de desplazamiento de turistas que contratan servicios de recorridos guiados en vehículos. A partir de una aproximación inicial al tema, el trabajo discute las propuestas tradicionales acerca de los tours guiados que los entienden como experiencias estandarizadas y pautadas. Asimismo, rescata la participación activa de los actores que forman parte de estos paseos. En términos más generales, el trabajo busca contribuir a la comprensión de los lugares turísticos, en esta ocasión, al considerar el movimiento de los turistas y reconocer especialmente las prácticas que le dan forma.

Palabras clave: movimientos turísticos; visitas guiadas; city tour; bus turístico; Salta; Argentina

\section{Moving Tourism places: displacement and guided tours in Salta (Argentina)}

\begin{abstract}
The article addresses the role of tourist movement in defining Salta (Argentina) as a tourist place. To achieve that goal, specific practices of displacement by tourists who hire guided tours were observed. As a preliminary study, the paper discusses traditional approaches to guided tours as highly standardized and prescribed experiences. Likewise, it highlights the active participation of the different actors taking part in these tours. In a broader sense, the paper aims at contributing to the understanding of tourist places considering tourist movement and to acknowledge the practices that shape it.
\end{abstract}

Keywords: tourist movement; guided tour; city tour; sightseeing bus; Salta; Argentina 


\title{
Lugares turísticos em movimento: deslocamentos $e$
} percursos guiados em Salta (Argentina)

\begin{abstract}
Resumo
0 artigo aborda o papel que realiza o movimento vinculado ao turismo, da cidade de Salta (Argentina), na sua conformação como destino turístico. Para tal, observam-se as práticas de deslocamento de turistas que contratam serviços em percursos guiados de carro. A partir de uma aproximação inicial ao assunto, o trabalho discute as propostas tradicionais sobre os tours guiados que os interpretam como experiências estandardizadas e pautadas. Porém, resgata a participação ativa dos atores que formam parte destes passeios. Em linhas gerais, o trabalho procura contribuir à compreensão dos lugares turísticos, nesta ocasião, ao considerar o movimento dos turistas e reconhecer especialmente as práticas que Ihe dão forma.
\end{abstract}

Palavras-chave: Movimentos turísticos; Visitas guiadas; City Tour; Ônibus turístico; Salta; Argentina

\section{Movimiento, recorridos organizados y lugares turísticos}

De manera reciente la Geografía y otras ciencias sociales han redescubierto el interés por discutir el desplazamiento y las diferentes formas de movilidad espacial. Esto ha ido de la mano de un cuestionamiento al tratamiento de los lugares como ámbitos estáticos y de una propuesta de considerarlos como intersecciones de diversos movimientos y flujos que le otorgan especificidad (Cresswell, 2002). Por su parte, los estudios turísticos, a pesar de abordar diferentes temas en torno a una práctica de desplazamiento espacial, sólo recientemente se han interesado por el movimiento (Franklin y Crang, 2001). En efecto, en la literatura abocada a estos temas prevalece un tratamiento de los destinos turísticos como ámbitos estáticos que excluyen una movilidad que parece acontecer fuera de ellos, o entre ellos y otros lugares.

Pero si consideramos que la movilidad es constitutiva de los lugares, que las prácticas de movilidad (como otras) colaboran en la producción del lugar (Cresswell, 2002), ¿qué papel juega el turismo como práctica de desplazamiento en la conformación de un destino turístico como tal y cómo incide el movimiento de los turistas en la dinámica general de ese 
lugar? Este trabajo busca abordar las formas que adquiere el movimiento, específicamente de los turistas, en estos lugares de destino. En efecto, la atención está puesta en los recorridos que visitan distintos puntos identificados como sitios de interés en una visita turística. Esto se analiza abordando el caso de la ciudad argentina de Salta (capital de la provincia homónima). Consolidada como destino turístico en las últimas décadas, la ciudad recibe visitantes que recorren principalmente su centro histórico. ¿Cómo es el movimiento por la ciudad que realizan los turistas? ¿Qué áreas transitan? ¿En qué puntos de la ciudad se detienen? ¿Qué hacen en ellos? ¿Qué particularidades tienen estos recorridos cuando son organizados por los servicios de tour guiados ofrecidos en la ciudad? ¿Cómo se vinculan estos recorridos con los procesos por los cuales se definen los atractivos del destino?

Teniendo en cuenta las preguntas expuestas, y a modo de primera aproximación, este trabajo tiene por objetivo analizar las prácticas de desplazamiento que caracterizan la visita turística en Salta en particular aquellas realizadas a través de servicios de tour guiado realizados en vehículo automotor que se ofrecen en la ciudad. Específicamente se intenta conocer: 1) cómo se construye la experiencia de aproximación a los atractivos y en general a la ciudad a partir de los recorridos guiados; 2) cuáles son las actividades propuestas a los turistas como parte del recorrido; 3) cómo los participantes de estos recorridos le dan forma a la experiencia turística.

Con ello se busca discutir y problematizar algunas de las características que adquiere la experiencia de desplazamiento por la ciudad que ofrecen estos servicios y, en último término, se procura aportar elementos para conocer la conformación del destino en relación con este tipo de movimiento. En este sentido, se espera contribuir con discusiones más amplias en torno a la relación entre movimientos turísticos y organización de los espacios turísticos.

Para esta investigación se definió una estrategia metodológica en la cual se procedió a la observación de las prácticas de desplazamiento de turistas por la ciudad de Salta que contratan servicios de recorridos guiados como el bus turístico y aquellos realizados en vehículos de tipo van (o "combi" como se los denomina en la ciudad)². Esta observación se realizó en dos sentidos: por un lado, se eligieron lugares específicos donde los recorridos suelen tener sus paradas y allí se observó la dinámica del movimiento y las actividades realizadas. Por otro lado, la observación de los desplazamientos se realizó en movimiento, participando de los recorridos ofrecidos por las agencias de turismo. En estas instancias de observación se procedió a registrar la información (verbal y visual) ofrecida por las empresas y los guías turísticos (la presentación, descripción e interpretación de los atractivos implicados en el paseo y las indicaciones y sugerencias 
respecto de la dinámica del viaje) como también los comentarios y acciones que realizaban los turistas en los trayectos y puntos de parada. También se realizó un registro fotográfico de los momentos que componían los tours. Además, se llevaron adelante entrevistas con los propios guías turísticos y con los responsables de algunas de las agencias de turismo que brindan estos servicios.

\section{Movilidad, recorridos y servicios turísticos guiados}

Propuestas recientes elaboradas desde la Geografía y las ciencias sociales han dejado de lado la consideración de los lugares como entidades estáticas para concebirlos como intersecciones de flujos y movimientos. En relación con esto, los lugares también han sido pensados como eventos marcados por un cambio progresivo y así concebidos como procesos en constante devenir (Massey, 1995; Cresswell, 2002; Crang, 2006). Esto ha llevado a poner la atención en las prácticas sociales que le dan forma a estos procesos para pensar los lugares como contextos de estas prácticas pero a la vez como resultado de ellas (Cresswell, 2002).

Esta idea sirve de punto de partida para recuperar algunas de las inquietudes respecto del vínculo entre movilidad y turismo. A partir de esta relación, que ha comenzado a ser explorada recientemente (Franklin y Crang, 2001; Allis, 2018), se procura abordar el desplazamiento comprendido como práctica y su papel en la conformación del lugar (de destino turístico) concebido él mismo como proceso (Sheller y Urry, 2004; Cresswell, 2010).

Itinerario, circuito, ruta, tour, camino forman parte de un campo semántico en torno a la idea de desplazamiento que abunda en la literatura dedicada al turismo. Buena parte de estos términos también han sido creados, instalados y definidos como parte de la industria turística al nombrar viejos (y nuevos) productos. Pero más allá de los usos corrientes de estos términos en el mundo de los negocios, o del propio uso cotidiano que se hace de ellos, las formas de desplazamiento vinculadas a itinerarios han sido poco discutida en la literatura académica interesada en comprender el turismo (Wang, 2006) y la que se interesa especialmente por su dimensión espacial (MacLeod, 2016). ¿Cuál es el lugar que los recorridos ocupan en el viaje? ¿Cómo es su relación con la experiencia turística? ¿A través de qué estrategias se presentan y efectivamente se concretan estos recorridos? ¿Cómo ellos forman parte de los procesos por los cuales los destinos turísticos se definen en tanto tales?

La literatura especializada en el turismo remite a diferentes cuestiones cuando refiere a los recorridos o itinerarios turísticos. Por un lado, ellos han sido comprendidos como un producto comercializado como paquete 
turístico que incluye un conjunto de servicios y actividades que vinculan origen y destino(s) como parte de un viaje (Wang, 2006). Por otro, se refieren a una propuesta o sugerencia para recorrer destinos que puede encontrarse en guías o folletos turísticos u otras formas de comunicación vinculadas con el viaje (Farías, 2011). Por último, los recorridos o itinerarios remiten a las formas en que efectivamente los turistas transitan por un destino o conjunto de destinos como parte de la experiencia del viaje (independientemente de si esto es producto de la comercialización de un paquete turístico) (Edensor y Holloway, 2008; Farías, 2010a, Farías, 2010b; Cunin y Rinaudo, 2008). Más allá de sus diferencias, todas estas ideas implican formas de organización temporal y espacial de la visita a destinos turísticos. Y esta organización enlaza un conjunto de imágenes e imaginarios geográficos acerca de los lugares visitados (que, en general, anticipan la visita turística) con la prestación de determinados servicios y la comercialización de distintos tipos de productos. Al tiempo que también se vincula con transformaciones y adecuaciones de los lugares para la permanencia y circulación de los turistas (creación y mantenimiento de infraestructura y equipamiento, por ejemplo).

Al adentrarse en la idea de itinerario turístico Wang (2006) afirma que éste organiza la experiencia turística en la medida en que constituye la arena en la cual esta experiencia es socialmente producida. Y esto implica, en las sociedades contemporáneas, su comercialización como una mercancía. En definitiva, el itinerario sería la forma de materializar experiencias que de otro modo son intangibles, de hacerlas comercializables en una propuesta que disminuye los riesgos de todo viaje turístico (Wang, 2006).

Otro de los aspectos que caracteriza a los recorridos o itinerarios es que constituyen productos de selecciones (MacLeod, 2016) que definen un conjunto concreto de atractivos y lugares, aquellos que se consideran dignos de ser visitados (en función de ciertas ideas, imágenes, valoraciones que los turistas tienen acerca del mundo). Como parte de estas selecciones, los itinerarios pueden ser definidos en torno a una temática particular pero, en cualquiera de los casos, se trata de un agregado de elementos que también cobra sentido como conjunto.

Los recorridos e itinerarios en ocasiones se expresan como propuestas que anticipan la visita turística. Antes del viaje los turistas suelen consultar algún tipo de información acerca de los destinos como, por ejemplo, los recorridos propuestos en guías turísticas y publicaciones oficiales que pautan las formas de moverse en los destinos a través de descripciones verbales de trayectos o de estrategias gráficas plasmadas en mapas (esto incluye atractivos a contemplar e interpretaciones ofrecidas: sugieren qué, cómo y dónde observar, detenerse, fotografiar, realizar compras, etc.). 
Lo comentado hasta aquí da cuenta de formas que "orientan" al turista acerca de cómo encarar los recorridos. En relación con esto, se ha señalado el carácter prescriptivo de ciertos itinerarios ofrecidos en tanto imponen un orden y un control a la experiencia turística (Meethan, 2001; Ritzer y Liska, 2002). Este tipo de interpretación ha alcanzado tanto a los recorridos sugeridos mediante acciones comunicativas como a los itinerarios ofrecidos por empresas y comercializados en la forma de paquete turístico o excursiones organizadas.

Las excursiones guiadas que aquí se analizan forman parte de este tipo de experiencias: ofrecen itinerarios organizados en torno a un conjunto ordenado (espacial y temporalmente) de atractivos, actividades e información sobre el destino. Ellos unen elementos individuales en una secuencia de visita que reúne tiempos de desplazamiento, lugares del destino y una narrativa que otorga sentido a la experiencia y al destino mismo. En general forman parte de lo que la literatura turística ha identificado como servicios altamente estandarizados, repetitivos y regulados (pautan las vías, la dirección del desplazamiento y las actividades realizadas) que constituirían ejemplos paradigmáticos de formas de predeterminar la experiencia turística (Larsen y Meged, 2013). En efecto, el paquete turístico y otras formas similares son consideradas la expresión más acabada de una propuesta cerrada con pocas opciones de elección para el turista (Ritzer y Liska, 2002) donde los trayectos y paradas están prefijados y las interpretaciones sobre los atractivos son transmitidos de manera unidireccional por quienes ofician de guías (Urry y Larsen, 2011).

Sin embargo, en las últimas décadas han surgido propuestas que invitaron a poner el acento en los turistas y sus posibilidades de ir más allá de lo institucionalmente propuesto. Ellas señalan la importancia de considerar las propuestas comerciales y su influencia en las formas que toma la experiencia turística, pero señalan también la necesidad de un análisis acerca de las prácticas vinculadas con viaje para ver cómo los propios turistas moldean sus experiencias (Crang, 1997).

Así, las formas en que resulta la experiencia turística pueden estar pautadas en tanto se atienen a ciertos guiones o roles prescriptos por la industria turística pero también ellas podrían eludir la norma (Edensor, 2001; Larsen y Meged, 2013). Estas propuestas, asimismo, evitan las interpretaciones que consideran a los turistas como meros espectadores $y$, por el contrario, los conciben como actores activos en la creación de esa experiencia (MacLeod, 2016).

Teniendo en cuenta estas discusiones, la investigación apunta a analizar los recorridos turísticos guiados para el caso de la ciudad de Salta junto con la información orientativa vinculada a la promoción, la propuesta de las propias empresas que brindan servicios para realizar los 
recorridos en vehículos y las formas en que efectivamente se realizan estos paseos.

\section{Recorridos turísticos por la ciudad de Salta}

La ciudad de Salta ha sido destino de viajes turísticos desde comienzos del siglo XX (Flores Klarik, 2012). En las últimas décadas, y acompañando procesos de crecimiento del turismo a nivel nacional, se convirtió en un importante centro de llegada y distribución regional de turistas. Además de esta función, la propia ciudad capital cuenta con una oferta de servicios y actividades que los turistas aprovechan en su estancia (la estadía promedio es de 2,5 días) ${ }^{3}$.

Las formas de visitar el centro histórico de Salta se consolidaron a través del tiempo en un proceso que implicó la creación y difusión de información turística que instaló ciertos lugares como puntos para visitar en una estadía en la ciudad. Las propuestas que se han colocado a disposición del turista para recorrer el centro histórico (a través de guías turísticas, folletos turísticos y artículos periodísticos) sugieren ciertas formas específicas de visitar Salta en un recorrido que parte de la plaza central e incluye las edificaciones históricas a su alrededor y en sus cercanías (Troncoso, 2020). Esto coincide con el tipo de atractivos en los que se ha apoyado el turismo en la ciudad que remiten fundamentalmente a la historia y la cultura local. Si se atiende a la promoción oficial realizada desde los gobiernos provincial y municipal allí se destacan como principales atractivos momentos, acontecimientos y figuras específicos de la historia local vinculadas al pasado pujante de la ciudad cuando se destacaba como importante centro comercial en la etapa colonial y como ámbito donde se desarrollaron eventos decisivos en relación con la independencia nacional. Otros atractivos incluyen algunas manifestaciones culturales vinculadas a la música folklórica, la gastronomía, las artesanías y la religiosidad (católica) (Troncoso, 2013). La plaza principal 9 de Julio es uno de los puntos más visitados ya que a su alrededor se concentran edificios emblemáticos, muchos de ellos vinculados con esta historia provincial como el Cabildo, el Centro Cultural América (ex sede de gobierno), la Catedral, el Museo de Arte Contemporáneo, el Teatro Victoria, el Hotel Salta y el recientemente creado Museo Arqueológico de Alta Montaña. A esto se suma la visita, a unas pocas cuadras de distancia, de la Iglesia de San Francisco y el Convento de San Bernardo. Suele agregarse también la concurrencia a la calle Balcarce (lugar de concentración de la oferta gastronómica, de entretenimiento y de venta de artesanías), al monumento a Martín Miguel de Güemes y al Cerro San Bernardo que flanquea la ciudad hacia el este. La visita que realizan los turistas a estos puntos de la ciudad toma 
varias formas. Una de ellas es el recorrido con el auxilio de algún tipo de información turística (guía turística, promoción oficial, indicaciones en la oficina de informes turísticos, consulta a páginas web y redes sociales, etc.). Esto se realiza a pie o en vehículo particular. En otras ocasiones, el desplazamiento se concreta a través de la contratación de algún servicio que brinda recorridos turísticos por la ciudad.

Específicamente los servicios de excursión guiados ofrecidos en vehículos organizan un recorrido que incluye buena parte de estos puntos de interés que han devenido atractivos de la ciudad. Las agencias de turismo encargadas de este servicio aseguran que los itinerarios han cambiado poco desde la década de 1970 (entrevista con responsables de agencia de viaje, septiembre 2013). El estado provincial, por su parte, sugiere al sector privado dedicado a este tipo de servicios los itinerarios a realizar (y la caracterización de los atractivos que incluyen) ${ }^{4}$. Así, puede pensarse que la consolidación de estos recorridos se ha construido en un proceso histórico que ha reunido las sugerencias, decisiones y acciones provenientes de diferentes actores entre los que se destacan el estado y el sector privado (agencias de viaje) dedicado a este tipo de servicios. Este proceso está marcado por cierta naturalización en la manera en que se recorre la ciudad (y los atractivos que estos recorridos incluyen) que es expresada por uno de los guías que realiza el servicio de city tour cuando afirma: "Es lógico los puntos en que se para porque son los atractivos, están en las guías" (entrevista personal, julio 2017).

Teniendo en cuenta estos servicios en particular, icómo es, efectivamente, este despliegue de turistas por la ciudad? ¿De qué manera se combinan modos de desplazamiento, sitios de visita y actividades?

\section{Servicios turísticos guiados y desplazamientos por la ciudad de Salta}

Una de las formas de recorrer el centro histórico de la ciudad de Salta es a través de la contratación del servicio del bus turístico que funciona desde 2008. El paseo se realiza en vehículos colectivos del tipo minibuses descapotados y de doble piso. El recorrido es fijo con una duración de dos horas y contempla una cantidad también fija de paradas. En la actualidad parte de la plaza 9 de Julio (frente al Cabildo) e incluye 12 paradas, la mayoría en el centro histórico ${ }^{5}$. En las paradas el vehículo se detiene para la observación y la tomas de fotografías, y eventualmente en algunos casos se permite el descenso de los pasajeros para fotografiar las construcciones. El servicio ofrece dos paradas más en el mirador de Portezuelo (10 minutos) y en el Mercado Artesanal (20 minutos) donde se comercializan artesanías $^{6}$. Para acompañar el viaje se distribuye un folleto con la información de los atractivos de cada parada ${ }^{7}$. El vehículo está equipado en su 
interior con dispositivo audiovisual que consta de una pantalla en la cual se proyectan imágenes de los atractivos de cada parada. El audio grabado anuncia las paradas y describe las particularidades de sus atractivos (en castellano e inglés). Las paradas del bus turístico están señaladas mediante postes en las veredas que indican el número y nombre de cada una de ellas y los atractivos cercanos.

Los recorridos turísticos por la ciudad de Salta también son ofrecidos por los tradicionales servicios en vans o "combis" llamados localmente city tour $^{8}$. Estos servicios parten habitualmente a las $15 \mathrm{hs}$ o $16 \mathrm{hs}$ con una duración de 4 horas. Los paseos se realizan en vehículos con capacidad para 10/12 personas con el formato de chofer/guía. El servicio lo ofrecen casi todas las agencias de viajes con locales comerciales en el centro de la ciudad. Ellas contratan guías (en general idóneos) que brindan el servicio con vehículos propios. Todos los servicios de city tour realizan el mismo recorrido (y las mismas paradas) con inicio en la plaza 9 de Julio con un recorrido similar al del bus turístico ${ }^{9}$. Las paradas donde los pasajeros descienden del vehículo son: el cerro San Bernardo, San Lorenzo y el Mercado Municipal (alrededor de 25 minutos en cada una). El guiado es en casteIlano (o bilingüe cuando entre los pasajeros hay turistas extranjeros).

Las caracterizaciones de la ciudad que componen el audio grabado del bus turístico y los relatos que presentan los guías en los city tours refuerzan en gran medida la selección de atractivos exhibidos por la promoción oficial. La sistematización de la información registrada en el contexto de los recorridos permitió identificar núcleos temáticos (asociados a hitos en el recorrido) que refieren a: la evolución histórica de la ciudad de Salta con fuerte énfasis en el período desde su fundación hasta fines del siglo XIX; los aspectos vinculados a la construcción de los edificios emblemáticos de la ciudad; la creación, el diseño y los usos de las áreas verdes; el relato de batallas en el contexto de la independencia nacional (con referencias a ciertos protagonistas como Belgrano y Güemes); los aspectos de la vida privada y pública de Güemes en particular su desempeño como militar; las festividades religiosas católicas; la producción cultural de la provincia (en especial los lugares y personalidades vinculadas a la música folklórica); los aspectos orográficos, climático e hídricos del valle del Lerma y los aspectos productivos de la provincia, entre otros.

Más allá de los aspectos generales de estos servicios, ¿qué interpretaciones pueden realizarse de estas iniciativas que organizan la circulación de turistas por la ciudad e intentan hacer significativa la experiencia? En principio, esta selección de sitios de la ciudad, y el efectivo traslado de los turistas hacia ello a través de recorridos establecidos, brindan la posibilidad del encuentro físico entre turista y atractivo. La presencia física del turista en el lugar donde se encuentra el objeto de interés habilita una forma 
de contacto (visual, en principio) que es posible por la mediación de este tipo de servicio (Farías, 2010a). Esto es acompañado de una narrativa (el guion creado para el recorrido) que les da sentido a cada atractivo de manera individual y al conjunto de ellos mostrando Salta como ciudad histórica, colonial, heredera de tradiciones, etc. Asimismo, este encuentro está fuertemente organizado en torno a la apreciación visual de los atractivos. Así, el punto de inicio (la plaza 9 de Julio; Figura $N^{\circ} 1$ ) y los de detención están destinados a la observación y a la toma de fotografías. La detención en estos sitios permite la observación fija y, en el caso del bus turístico, también en altura desde un punto de vista elevado (Farías, 2010a) (Figura $\mathrm{N}^{\circ} 2$ ). Los turistas, en estos lugares, se dedican a la observación de monumentos o edificaciones y a la generación de sus propias imágenes fotográficas (Figuras $\mathrm{N}^{\circ} 2$ y N $\left.\mathrm{N}^{\circ} 3\right)^{10}$. A su vez, se encuentran con otros turistas, muchos de los cuales han contratados servicios similares que realizan los mismos recorridos, con las mismas paradas en los mismos horarios. Esto genera la presencia simultánea de visitantes y vehículos en esos sitios (Figuras $\mathrm{N}^{\circ} 3$ y $\mathrm{N}^{\circ} 4$ ).

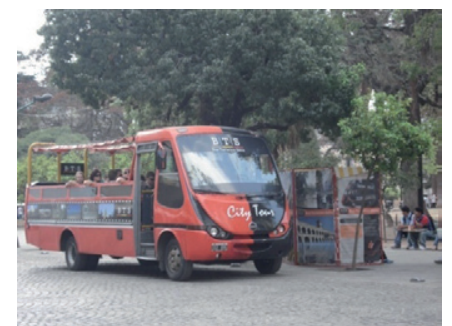

Figura $\mathrm{N}^{\circ} 1$. Bus turístico en el punto de partida (plaza 9 de Julio). Registro durante el trabajo de campo, septiembre de 2012.

Fotografía de la autora

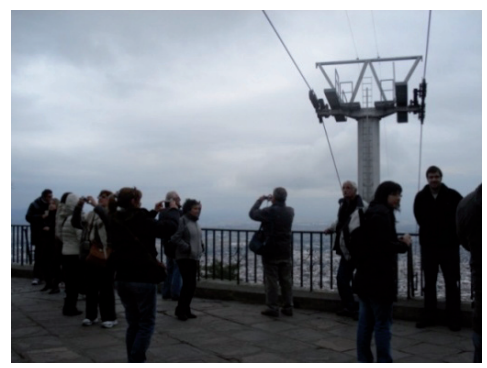

Figura $\mathbf{N}^{\circ} \mathbf{3}$. Turistas en la cima del cerro San Bernardo. Registro durante el trabajo de campo, mayo de 2014. Fotografía de la autora

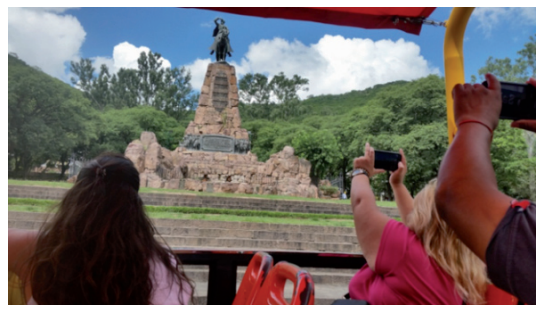

Figura $\mathbf{N}^{\circ} \mathbf{2}$. Turistas observando y tomando fotografías desde el bus turístico (Monumento a Güemes). Registro durante el trabajo de campo, febrero de 2016. Fotografía de la autora

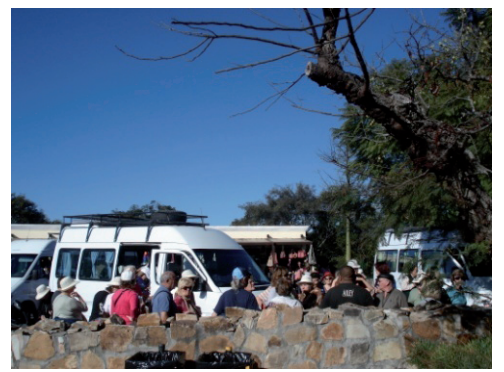

Figura $\mathrm{N}^{\circ} 4$. Vehículos del servicio de city tour (cerro San Bernardo). Registro durante el trabajo de campo, junio de 2011. Fotografía de la autora 
La predominancia del sentido de la vista, y de las actividades que lo involucran, ha sido largamente señalada en los estudios del turismo. Urry (1990) rescata su importancia en tanto sentido que organiza los destinos. En efecto, en su propuesta los lugares son adecuados para ser mirados y los turistas son "adiestrados" para ver (Franklin, 2003), para tener una aproximación visual a los atractivos y los destinos en general. Los servicios de excursiones se organizan con esta lógica ya que los recorridos parecen ser articulados en torno a la observación. Los guías turísticos, las grabaciones del bus turístico (y eventualmente los choferes de este servicio) invitan a observar señalando en determinadas direcciones para identificar algo que debe ser visto, que debe ser apreciado visualmente ${ }^{11}$. La preeminencia de la apreciación visual de atractivos, y su registro mediante fotografías, queda evidenciada cuando los choferes y guías anuncian las paradas: "Si alguien desea bajar a hacer una foto..." (city tour, mayo de 2014); "paramos para sacar una foto"; "pueden bajar a hacer fotos", "hacemos la foto y continuamos" (city tour, septiembre de 2013); "si quieren bajar a hacer una fotito..." (bus turístico, junio de 2011) ${ }^{12}$.

Los puntos de parada de estos recorridos también fueron acondicionados con este fin: son sitios arreglados para ser contemplados (por ejemplo, mediante tareas de embellecimiento de edificios históricos ${ }^{13}$ ), ambientes que se disponen especialmente para la presencia de turistas y para sus actividades de observación y registro fotográfico (Edensor, 2001) como los miradores diseñados y equipados (con infraestructura y servicios) en el cerro San Bernardo y en el mirador de Portezuelo.

La apreciación visual que ofrecen estos servicios se combina con la posibilidad de la observación en movimiento (y con la visión panorámica en el caso del bus turístico). Este tipo de vehículos (junto con los trenes y los automóviles) han sido pensados como tecnologías de visualización específicas en tanto habilitan formas particulares de observar y experimentar visualmente los lugares en comparación con otras (la observación fija en el espacio) (Larsen, 2001) que aporta un elemento distinto a la apreciación visual de atractivos (y al servicio ofrecido).

En contraposición con los puntos de parada hay trayectos y momentos para los cuales los servicios no invitan a mirar. Justamente estos tramos se corresponden con áreas que quedaron fuera de las selecciones históricas de los atractivos de la ciudad. La condición de "muertos" de estos tiempos ha sido ya discutida (véase Cresswell, 2010) pero además se asocian a "espacios muertos" (turísticamente hablando) en la medida en que nada se dice en amplias áreas de la ciudad por donde se transita. En el caso de los tours guiados en Salta estos trayectos y tiempos muertos suelen "Ilenarse" con descripciones o narraciones más extensas acerca de aspectos 
generales de la ciudad o la provincia ${ }^{14}$ (estos trayectos también son los elegidos para musicalizar el viaje).

En términos generales, estas formas de recorrer la ciudad muestran un carácter repetitivo, y en este sentido también cierta predictibilidad, en tanto involucran rutas y paradas preestablecidas que, a su vez, responden a narrativas turísticas del lugar ya consolidadas. En relación con esto, puede pensarse que la presencia de los servicios forma parte de "coreografías" (Edensor, 2001) en las que convergen servicios similares que se desplazan a horarios y velocidades similares, se detienen en los mismos lugares con turistas que realizan las mismas actividades. Esto habla de cierta estandarización que caracteriza a estos servicios. De hecho, las agencias lo ofrecen en estos términos, como un producto estándar y económico (entrevistas a agencias de viaje, febrero de 2016). Pero, como se verá más adelante, esta idea también puede ser puesta en tensión.

Estos recorridos turísticos, a su vez, tienen protagonistas que también participan en la forma que toma cada experiencia concreta. Los guías turísticos encargados del servicio de city tour (y en menor medida los choferes del bus turístico ${ }^{15}$ ) aportan elementos para singularizar estos servicios. Así, por ejemplo, manejan los tiempos del viaje al modificar la velocidad del recorrido en función de la aparición en el trayecto de algunos de los atractivos que se busca identificar y destacar. La velocidad es acondicionada buscando modular la experiencia turística (Farías, 2010a) para lograr cierta fluidez en la sucesión de atractivos que no son equidistantes (esto también toma en cuenta el tránsito de la ciudad que no es constante en todo el recorrido).

El manejo de una idea global del tiempo de la excursión les permite tomar decisiones respecto del tiempo en las paradas, el horario de llegada a los sitios, la extensión de las narraciones que desarrollan, etc. Así, por ejemplo, en uno de los viajes realizados en el servicio de combi (septiembre de 2013), un día fuera de temporada, de escaso tránsito, la guía ofreció una parada extra para la toma de fotografías en el convento San Bernardo, mientras que en otra ocasión uno de los guías entrevistados relataba:

Demora de dos turistas 15 minutos más en el cerro San Bernardo: eso hace que se llegue de noche a San Lorenzo. Las cinco chicas que cambian el punto de recogida a último momento: los tiempos se acortan, se empieza con el relato más tarde y hay que apurarlo (entrevista a guía de servicio de city tour, julio de 2017).

Asimismo, contemplan las diferentes circunstancias que le impone cada viaje en particular. Más allá de la reiteración de un guion aprendido, practicado y perfeccionado hay margen para la improvisación. Por ejem- 
plo, frente a los embotellamientos o las detenciones involuntarias ensayan formas de agregar información complementaria ${ }^{16}$. Así, los guías diseñan sus propios guiones, al combinar la información disponible de diferentes maneras, al organizarla en distintas secuencias o al complementarla con información adicional. También ensayan estrategias para hacer más entretenido el paseo ${ }^{17}$. Asimismo, hay ciertas elecciones, en general, acerca de qué características quieren imprimirle al tour, en ocasiones sopesando las apreciaciones que tienen del público/turista para quien se organiza la excursión ${ }^{18}$.

Así, a partir de ciertas coordenadas que fijan el carácter repetitivo y uniforme de este tipo de viajes, los guías otorgan ciertas particularidades a los paseos ya sea en pos de atender situaciones imprevistas, ya sea por complacer a los turistas como parte de su estrategia laboral (Larsen y Meged, 2013).

La figura de los guías también introducen una cuestión que se ha señalado con frecuencia en relación con los servicios turísticos guiados: el carácter unidireccional de la información que se genera durante el viaje (Urry y Larsen, 2011) en tanto ellos detentan el rol de voz autorizada (y casi única) en la forma del guion del paseo (Farías, 2010a); como se señaló anteriormente, señalan, por ejemplo, hacia dónde mirar (y eventualmente fotografiar) en cada momento. Los guías (y eventualmente el conductor en el caso del bus turístico) son quienes también "administran" las actividades que realizan los turistas durante el recorrido. Ellos orientan qué se hace, cómo, cuándo, dónde y por cuánto tiempo ${ }^{19}$, establecen el descanso en el relato ${ }^{20}$ y administran los momentos en que los turistas intervienen en ellos: preguntan si hay alguna consulta o duda (city tour, mayo de 2014 y febrero de 2016), les otorgan la palabra e incluso piden silencio cuando los turistas conversan durante el relato (city tour, septiembre de 2013) ${ }^{21}$.

Los guías turísticos tienen un rol central en la organización de los recorridos turísticos, en la implementación de los aspectos normativos de este tipo de paseos y en la elaboración de interpretaciones acerca del destino y sus atractivos. En lo observado en el caso de Salta ellos acompañan lo institucionalmente propuesto para recorrer la ciudad, a la vez que le imprimen algunas especificidades a cada viaje siendo activos creadores de la experiencia que se genera en el paseo.

Sin embargo, el trabajo de los guías interactúa con las acciones de los propios turistas. ¿Cómo es la participación de los turistas en los tours guiados? ¿Cómo le dan forma a su propia experiencia de viaje? En las propuestas que han hecho hincapié en los aspectos prescriptivos de los tours guiados se ha señalado la actitud pasiva de los turistas, su condición de receptores de información, que escuchan y observan según lo propuesto 
(Larsen y Meged, 2013). La observación de los recorridos guiados en Salta permite poner en tensión estas lecturas. Claramente los turistas saben que se trata de una experiencia pautada, condicionada, donde tanto los tiempos de la excursión, como los lugares de parada o las rutas de desplazamiento ya están fijas de antemano (de hecho, esto se explicita al momento de contratar el servicio). Pero la observación durante estos paseos ha permitido ver que la actitud de atención absoluta, de "recibir" la propuesta del tour como algo cerrado y definido no es la única entre los turistas y que ellos, de distintas maneras, inciden en la forma que toma la experiencia del recorrido por la ciudad 22 .

Así, por ejemplo, los turistas preguntan por los temas que les interesan y eso hace que el relato tal cual estaba planeado se interrumpa, se haga más sintético o tome otro contenido. En los recorridos en que se participó como parte de la investigación los turistas introducían temas variados de su interés. Algunos remiten a información de tipo práctica que facilita su estadía en la ciudad (por ejemplo, en varias oportunidades solicitaron recomendaciones de locales gastronómicos y peñas, demandaron información extra acerca de la visita a museos, consultaron sobre excursiones a otros destinos regionales, etc.). Pero también se han mostrado interesados en conocer aspectos o eventos vinculados con la ciudad o la provincia. En uno de los viajes buena parte recorrido se ocupó en responder a las consultas de una turista respecto de la situación socioeconómica de la ciudad de Salta y la provincia en general. Estas preguntas fueron disparadas por la observación de manifestaciones y reclamos realizados por docentes provinciales en la plaza 9 de Julio (city tour, mayo de 2014). En otra ocasión, en el trayecto de ascenso al cerro San Bernardo los turistas observaron las condiciones de la vegetación afectada por un incendio sucedido unos meses antes. Las múltiples consultas sobre este tema introdujeron un aspecto nuevo al relato que implicó una reducción y supresión de los temas que habitualmente son tratados en ese tramo del recorrido y el agregado de otros (acerca de ese evento, de otros similares y sobre del manejo del cerro como área protegida con categoría de Reserva Municipal) (city tour, septiembre de 2013).

La observación por parte de los turistas de eventos específicos (o de sus consecuencias visibles) otorgó un nuevo contenido a los relatos previstos. Así, los turistas inciden en ellos a partir de inquietudes previas o incluso a partir de la observación (en el propio recorrido) de aquellos eventos o aspectos de lo que nada se dice. Ellos no solo demandan a los guías ampliar información sobre alguna cuestión, también suman nuevos temas, a veces vinculados con aquello que ven sin que haya sido señalado como digno de observar, aquello que ellos observan de los espacios sobre lo que nada se dice. Los turistas le dan forma al guion que manejan los guías a partir de sus preguntas e intervenciones y en este proceso partici- 
pan en las formas en que la ciudad es presentada en este tipo de visitas guiadas. Incluso, en algunos casos la información que ofrecen los turistas es replicada o comentada en otros viajes ${ }^{23}$.

Más allá de la incidencia del turista en la información que se genera en el paseo, a partir de la participación de este tipo de excursiones se constató que con frecuencia los visitantes suelen demandar detenerse en lugares no previstos, o permanecer más tiempo en los lugares de paradas. Excepcionalmente se accede a estos pedidos, a veces con el consenso del resto de los viajeros. Esto introduce cambios en el recorrido (en sus tiempos y en la experiencia en sí) que se alejan de aquello prescripto en las formas habituales que toma este servicio.

Las prácticas de desplazamiento organizadas en servicios de city tour son formas altamente estandarizadas de recorrer la ciudad. En este sentido, responden al carácter repetitivo y predictivo asociado a los tours guiados. Sin embargo, se puede pensar que los turistas también son, en parte, partícipes activos de su experiencia turística: los recorridos guiados no anulan la posibilidad (cambiante según las circunstancias y las especificidades de cada viaje) que ellos tienen de co-crear la experiencia turística (Larsen y Meged, 2013) como una forma específica de apropiarse del lugar visitado. En este sentido es que las formas concretas de involucrarse en la experiencia turística responden a lo pautado a la vez que pueden desafiarlo (Edensor, 2001).

\section{Recorridos guiados: hilvanando la geografía turística de la ciudad de Salta}

La investigación ha procurado, de manera inicial, dar cuenta de las prácticas de desplazamiento de los turistas en la ciudad de Salta a partir de la contratación de servicios de recorridos turísticos guiados. Esto se realizó con el objeto de conocer las características que toma esta experiencia, las actividades desarrolladas en estos paseos y la participación de sus protagonistas en ello. En relación con esto, se ha señalado que estas formas de movimiento concretadas por los servicios turísticos guiados reúnen un conjunto de puntos de la ciudad tematizados en torno a los aspectos que han consolidado la atractividad turística de Salta. Y que esta aproximación a los atractivos está marcada por una forma de apreciación que es eminentemente visual. Asimismo, puede decirse que estos servicios, con sus formas específicas de organización espacial y temporal, definen formas repetitivas y estandarizadas de recorrer la ciudad. Sin embargo, estas coreografías que se despliegan exhiben particularidades que dan cuenta de una combinación de eventos y participantes que define las especificidades de cada viaje. 
A partir de esto, el trabajo brinda algunos puntos para continuar la indagación acerca de este tipo de experiencias turísticas que han sido entendidas como eminentemente estandarizadas. Las experiencias pensadas y brindadas con estas características, ¿son necesariamente experimentadas así por los turistas?, ise puede asumir que los servicios estandarizados se corresponden con un turista también estandarizado? (Larsen y Meged, 2013).

Asimismo, el trabajo procura ofrece elementos para continuar en el camino de la comprensión de las vinculaciones entre movimiento, turismo y lugares. Los recorridos implican el movimiento de los turistas en el espacio, el despliegue de narrativas vinculadas al destino y un conjunto diverso de acciones e interacciones que moldean las forma que toma la experiencia turística de lugares (MacLeod, 2016). En relación con esto, los recorridos se adecuan a la vez que definen los entornos en los que se concretan, los sentidos a ellos asociados y las prácticas en ellos llevadas adelante; en definitiva, definen los lugares (en tanto destinos turísticos) junto con otros procesos que colaboran en la misma dirección. Esto otorga elementos para pensar y continuar el análisis de las diferentes maneras en que los destinos turísticos (lejos de ser concebidos como estáticos, cerrados e inmóviles) pueden comprenderse como lugares en constante devenir producidos a partir de prácticas sociales concretas (entre ellas las vinculadas al movimiento de los turistas).

\section{Referencias bibliográficas}

Allis, T. (2018). Movilidad y turismo. En D. Zunino Singh, G. Giucci y P. Jirón (Eds.), Términos clave para los estudios de movilidad en América Latina (pp. 131-137). Buenos Aires: Biblos.

Crang, M. (1997). Picturing practices: research through the tourist gaze. Progress in Human Geography, 21(3), 359-373.doi: 10.1191/030913297669603510

Crang, M. (2006). Circulation and emplacement the hollowed-out performance of tourism. En C. Minca y T. Oakes (Eds.), Trave/s in paradox. Remapping tourism (pp. 4764).Lanham: Rowman \& Littlefield.

Cresswell, T. (2002). Introduction: Theorizing place. Thamyris/Intersecting. 9, 11-32. doi: 10.1163/9789004333451_003

Cresswell, T. (2010). Towards a politics of mobility. Environment and Planning D: So- ciety and Space, 28, 17- 31. doi: 10.1068/ d11407

Cunin, E. y Rinaudo, C. (2008). Consuming the city in passing: guided visits and the marketing of difference in Cartagena de Indias, Colombia. Tourist Studies, 8(2), 267286. doi:10.1177/1468797608099252

Edensor, T. (2001). Performing tourism, staging tourism: (re)producing tourist space and practice. Tourist Studies, 1, 59-82. doi: $10.1177 / 146879760100100104$

Edensor. T. y Holloway, J. (2008). Rythmanalysing the couch tour: the Ring of Kerry, Ireland. Transactions of the Institute of British Geography, 33(4), 483-501. doi: 10.1111/j.1475-5661.2008.00318.x

Farías, I. (2010a). Spatial arrangements and mediation in sightseeing bus-tours. En J. Richter (Ed.), The tourist city Berlin: Tour- 
ism and architecture (pp. 200-219), Berlín: Braun.

Farías, I. (2010b). Sightseeing Buses: Cruising, Timing and the Montage of Attractions. Mobilities, 5(3), 387-407. doi: 10.1080/17450101.2010.494842

Farías, I. (2011). Tourist maps as diagrams destination space". Space and Culture, 14(4), 398-414. doi: $10.1177 / 1206331210392682$

Flores Klarik, M. (2012). La construcción de Salta "la linda". Apuntes para la construcción de una antropología del turismo. Saarbrücken: Editorial Académica Española.

Franklin, A. (2003). Tourism: an introduction. Londres: Sage.

Franklin, A. y Crang, M. (2001) The trouble with tourism and travel theory?. Tourist Studies, 1(1), 5-22. doi $10.1177 / 146879760100100101$

Larsen, J. (2001). Tourism Mobilities and the Travel Glance: Experiences of Being on the Move. Scandinavian Journal of Hospitality and Tourism, 1(2), 80-98. doi:10.1080/150222501317244010

Larsen, J. y Meged, W. (2013). Tourists CoproducingGuided Tours. Scandinavian Journal of Hospitality and Tourism, 13(2), 88-102. doi: 10.1080/15022250.2013.796227

MacLeod, N. (2016). The role of trails in the creation of tourist space. Journal of Heritage Tourism, 12(5), 423-430. doi: 10.1080/1743873X.2016.1242590

Massey, D. (1995). The conceptualization of place. En: D. Massey y P. Jess (Eds.), A place in the world? Places, cultures and globalization (45-85). Oxford, Oxford University Press/The Open University.

Meethan, K. (2001). Tourism in global society. Place, culture, consumption. Nueva York: Palgrave.

Ministerio de Cultura y Turismo de Salta (2013). Circuito ciudad de Salta y alrededores. Material orientativo y de consulta para el examen de guías idóneos, Salta.
Ministerio de Cultura, Turismo y Deportes de Salta (2018). Informe de gestión 2018. Salta.

Ministerio de Cultura, Turismo y Deportes de Salta (2019). Resultado de un trabajo de todos. Salta.

Ministerio de Turismo de Salta (2004). Informe Estadístico de la provincia de Salta. Año 2004. Salta.

Ritzer, G. y Liska, A. (2002).'Mcdisneyization' and 'post-tourism': complementary perspectives on contemporary tourism. En C. Rojek y J. Urry (Eds.), Touring cultures, Transformation of tourism and theory (pp.96-109). Londres: Routledge.

Sheller, M. y Urry, J. (Ed.) (2004). Tourism mobilities. Places to play, places in play. Londres y Nueva York: Routledge.

Troncoso, C. (2013). Espacio patrimonial, espacio de deleite visual y consumo. Transformaciones patrimoniales recientes y turismo en la ciudad de Salta (Argentina). Espaço e Geografia, 16(2), 641-674.

Troncoso, C. (2020). El desplazamiento turístico a través de propuestas de recorridos e itinerarios. La ciudad de Salta (Argentina) y la consolidación de los paseos por su centro histórico, Claves. Revista de Historia, 6(10), 95-119.

Urry, J. (1990). The tourist gaze. Leisure and Travel in Contemporary Societies. Londres: Sage.

Urry, J. y Larsen, J. (2011). The tourist gaze 3.0. Londres: Sage.

Wang, N. (2006). Itineraries and the tourist experience". En C. Minca y T. Oakes (Eds.), Travels in paradox. Remapping tourism (6576). Maryland: Rowman \& Littlefield Publishers.

\section{Notas}

1 Licenciada y Doctora en Geografía (Universidad de Buenos Aires). Investigadora adjunta en CONICET. Docente de la ca- 
rrera de Geografía en la cátedra Geografía Social (Facultad de Filosofía y Letras, Universidad de Buenos Aires).

2 Como parte de las decisiones metodológicas tomadas se intentó que la participación en los tours abarcara situaciones diferentes. Para ello se eligió acompañar los recorridos en temporada alta y en temporada baja, en diferentes momentos del día, en servicios que ofrecían guiado solo en castellano y otros con la opción bilingüe (castellano-inglés), en viajes con diferentes guías, etc. Estas decisiones buscaban registrar diferentes situaciones en que se realizaban los tours pero también dar cuenta de las regularidades que marcaban este tipo de experiencias. Las excursiones en los servicios de tours guiados se realizaron durante los años 2011, 2012, 2013, 2014, 2016 y 2017.

3 Las estadísticas oficiales más recientes disponibles señalan que la llegada de turistas a la provincia se ha incrementado de 285.000 en 1995 a 1.817 .968 en 2018. También aumentaron los servicios vinculados con el turismo: las plazas hoteleras pasaron de 6.523 en 1998 a 21.317 en 2019 (de este total la ciudad concentra alrededor del $60 \%$ de estas plazas) y la cantidad de agencias de viaje de 21 en 1994 a 182 en 2019 (más del $80 \%$ se localiza en la capital) (Ministerio de Turismo 2004; Ministerio de Cultura, Turismo y Deportes, 2018; Ministerio de Cultura, Turismo y Deportes, 2019).

4 Esto puede verse en el material orientativo y de consulta para el examen de inscripción en el registro provincial de guías turísticos (Ministerio de Cultura y Turismo, 2013).

5 Ellas son: plaza Belgrano, calle Balcarce/ estación del ferrocarril General Belgrano (desde donde parte el servicio turístico del Tren de las Nubes), Monumento a la Batalla de Salta, Palacio Legislativo, Convento San Bernardo, el Monumento a Güemes, mirador de Portezuelo, Parque San Martín, Iglesia de la Viña, Paseo de los Poetas, Mercado Artesanal y Cabildo.
6 Durante la temporada alta (verano e invierno) se han llegado a realizar hasta seis salidas diarias; el resto del año se realizan solo dos. También se ofrece un servicio nocturno en temporada alta (viernes y sábados) que incluye cena y show en alguna peña de la ciudad.

7 Se trata de una guía escrita en español, inglés y francés que describe y presenta a través de fotografías los atractivos de cada punto de detención.

8 En el trabajo se recupera esta denominación local y se llama city tour exclusivamente a estos servicios (para diferenciarlos del que brinda el bus turístico).

9 El recorrido incluye: la Iglesia de San Francisco, el Convento San Bernardo, el Parque San Martín, el cerro San Bernardo, el Monumento a Güemes, el Monumento a la Batalla de Salta, la localidad cercana de San Lorenzo y el Mercado Artesanal.

10 En el caso del bus turístico la observación directa de los atractivos se complementa con las imágenes que se ofrecen en la pantalla al interior del vehículo. En ellas es posible ver los atractivos desde otros ángulos, en otras condiciones climáticas o de iluminación, además de sumar algunos de atractivos que no están incluidos en el paseo.

11 Los guías indican: "Hacia la izquierda en seguida van a ver la ciudad, esta es la vista cuando suben por el teleférico, ahí está el cable y allá está la ciudad" (city tour, febrero de 2016); "En caso que no tengan tiempo de volver a este lugar, pueden bajar a hacer fotos de la puerta, la capilla [del Convento San Bernardo]; se ve [la iglesia de] San Francisco, el campanil hacia atrás" (city tour, mayo de 2014).

12 Otros sentidos no están involucrados en este tipo de experiencias aunque ellos puede ser estimulados -o evocados- en estos recorridos (la utilización de música folklórica para amenizar el viaje es uno de los elementos que se utilizan para darle forma a esta experiencia de "inmersión" en la Salta turística). 
13 Esto ha sido parte del programa de renovación del centro histórico de la ciudad a comienzos de la década de 2000 seguido por la designación del área como Bien de Interés Arquitectónico y Urbanístico de la Provincia de Salta (2009) que también definieron a Salta como una ciudad para apreciar visualmente (Troncoso, 2013).

14 Aspectos relacionados con la figura de Güemes, por ejemplo, suelen contarse en estos trayectos.

15 En el caso del bus turístico, donde los conductores podrían limitarse a esa tarea, en ocasiones se muestran predispuestos a hacer de guías turísticos ofreciendo información adicional acerca de atractivos, eventos en la ciudad, lugares gastronómicos, días y horarios de visita de museos, etc.

16 Aunque algunos prefieren un relato conciso y dejan lugar al silencio en tramos amplios del trayecto. Así lo expresaba uno de los guías: "Yo prefiero limitarme a lo que tengo que hacer. Lo básico, y si alguien me pregunta, yo modestamente soy solvente como para responder, ampliar la información" (entrevista a guía turístico de servicio de city tour, febrero de 2016).

17 En ocasiones recitan poemas o entonan canciones, administran la información dosificándola a lo largo del recorrido e introducen detalles anecdóticos que captan la atención de los turistas.

18 Uno de los guías explica: "Hay algunos que son más de hacer chistes, más chabacanos. Si le toca un clase media, clase media baja, un cordobés, se va a enganchar que va a volver con la mandíbula que le duele de la risa. Pero le toca uno más culto y no sabe acompañarlo" (entrevista guía turístico de servicio de city tour, julio de 2017).

19 "Hacemos la foto y continuamos" (city tour, febrero de 2016); "En este lugar ocupamos unos 25 minutos así que sería interesante que 5:25 estén de regreso así continuamos con la visita" (city tour, mayo de 2014).
20 "Bueno, los dejo un ratito con música, ya llegamos enseguida al Mercado Artesanal" (city tour, septiembre de 2013).

21 El carácter unidireccional de la información generada también es facilitado por los dispositivos utilizados. En el bus turístico el uso de la grabación emitida por parlantes prácticamente "anula" otro sonido que pueda generarse en el viaje. En el caso de los servicios de las combis, la utilización del micrófono juega el mismo papel: claramente se impone por sobre otros sonidos (incluidas voces) que se producen dentro y fuera del vehículo.

22 Otros elementos también cuestionan al turista como mero receptor de la información en la medida en que simplemente se ocupan de otras actividades durante el viaje: conversan, intercambian información de tipo práctica, entablan conversaciones telefónicas con familiares y amigos, resuelven cuestiones laborales, duermen, etc.

23 Durante uno de los tours la guía afirmaba que: "Tengo pasajeros que me han hecho ver algo que... yo lo veía pero bueno, no había abierto los ojos bien, no me había dado cuenta. No sé si ustedes se dieron cuenta. En donde me decían que se notan dos Saltas. Desde la calle Caseros hacia el norte es una, es toda esta, y de la calle Caseros hacia el sur es otra Salta" (city tour, mayo de 2014). 